\title{
Role of growth differentiation factor 11 in development, physiology and disease
}

\author{
Yonghui Zhang ${ }^{1,2}$, Yong Wei ${ }^{3}$, Dan Liu ${ }^{1,2}$, Feng Liu' ${ }^{2}$, Xiaoshan Li ${ }^{1,2}$, Lianhong Pan ${ }^{2}$, Yi Pang ${ }^{2}$ \\ and Dilong Chen ${ }^{2}$ \\ ${ }^{1}$ Department of Basic Medical Science, Chongqing Three Gorges Medical College, Chongqing, China \\ ${ }^{2}$ Chongqing Engineering Research Center of Antitumor Natural Drugs, Chongqing, China \\ ${ }^{3}$ College of Electronic and Information Engineering, Chongqing Three Gorges University, Chongqing, China
}

Correspondence to: Dilong Chen, email: cqsxyz1988tg@163.com

Keywords: GDF11, signaling, function

Received: November 30, 2016 Accepted: July 28, 2017 Published: August 14, 2017

Copyright: Zhang et al. This is an open-access article distributed under the terms of the Creative Commons Attribution License 3.0 (CC BY

3.0), which permits unrestricted use, distribution, and reproduction in any medium, provided the original author and source are credited.

\begin{abstract}
Growth differentiation factor (GDF11) is a member of TGF- $\beta$ /BMP superfamily that activates Smad and non-Smad signaling pathways and regulates expression of its target nuclear genes. Since its discovery in 1999, studies have shown the involvement of GDF11 in normal physiological processes, such as embryonic development and erythropoiesis, as well as in the pathophysiology of aging, cardiovascular disease, diabetes mellitus, and cancer. In addition, there are contradictory reports regarding the role of GDF11 in aging, cardiovascular disease, diabetes mellitus, osteogenesis, skeletal muscle development, and neurogenesis. In this review, we describe the GDF11 signaling pathway and its potential role in development, physiology and disease.
\end{abstract}

\section{INTRODUCTION}

Growth differentiation factor (GDF11), also called as bone morphogenetic protein 11(BMP11) belongs to the transforming growth factor- $\beta$ (TGF- $\beta$ ) superfamily. GDF11 was first reported in 1999 as a novel differentiation factor for odontoblasts [1]. Since then, many studies have investigated its distribution, structure and signaling mechanisms. Over the past 19 years, the role of GDF11 has been investigated in developmental biology and diseases such as anemia and cancer. Recent studies reported that GDF11 was a rejuvenation factor that reversed age-related heart hypertrophy and improved brain capillary and muscle function [2-4]. However, there are contradictory reports regarding the rejuvenating effects of GDF11. Restoring GDF11 in old mice had no effect on cardiac function and GDF11 had deleterious effects in aging skeletal muscle [5-6]. Additionally, there are contradictory reports regarding GDF11 function in cardiovascular disease, diabetes mellitus, osteogenesis, skeletal muscle development and neurogenesis. Therefore, in this review, we describe the GDF11 signaling pathway and its role in development, erythropoiesis, aging, cardiovascular disease, diabetes mellitus, cancer and other diseases. We also highlight the various controversies regarding the role of GDF11 in human physiology and diseases.

Discovery, formation and distribution of GDF11

Discovery of GDF11

McPherron et al. discovered myostatin (GDF8 or MSTN), another TGF- $\beta$ family member, which was closely related with GDF11 [7]. In 1999, using MSTN as a probe, the team cloned mouse and human GDF11 [8]. In the same year, using rat incisor dental pulp RNA as a template and degenerate primers based on the conserved mature BMP and GDF sequences, Nakashima et al. showed that GDF11 was first expressed 8.5 days post-coitus, with its highest expression in tail bud, and predicted the amino acid sequences of rat and mouse GDF11 [1]. Gamer et al. cloned human and mouse GDF11 using a bovine BMP-related sequence to design primers and demonstrated its role in patterning in both mesodermal and neural tissues [9].

Structure and formation of GDF11

The GDF11 gene was mapped to human chromosome 12q13.2 by aligning the GDF11 sequence 
(GenBank AF100907) with the genomic sequence (GRCh38). It encodes a 407 amino acid protein with a signal sequence for secretion, an RXXR proteolytic processing site, and a carboxyl terminal region containing a highly conserved pattern of cysteine residues [9]. The GDF11 protein is first cleaved by pro-protein convertase subtilisin/kexin type 5 (PCSK5) to form a non-covalent latent complex, which contains $\mathrm{N}$-terminal inhibitory pro-domain and two disulfide-linked carboxyl-terminal active domain [10-11]. The members of BMP1/Tolloid family of metalloproteinases then cleave the latent complex at a specific site to activate GDF11 (Figure 1). Ge et al. showed that the proteolytic processing of the precursor $50 \mathrm{kD}$ GDF11 protein between gly119 and asp120 resulted in release of a $37 \mathrm{kD}$ pro-domain and a $12.5 \mathrm{kD}$ mature GDF11 [12]. The GDF11 is transported and stored in vesicles such as lipid droplets, endosomes, lysosomes and peroxisomes (Figure 2). It is possible to be translated in the rough endoplasmic reticulum, processed in the Golgi apparatus and then sorted to lysosomes, peroxisomes or secretion from the cells in transport vesicles, which needs more research to verify. Mature human, rat and mouse GDF11 have $90 \%, 88 \%$ and $90 \%$ amino acid sequence identity to GDF8, respectively $[1,9]$. Besides, human and mouse GDF11 proteins are 99.5\% identical [9].

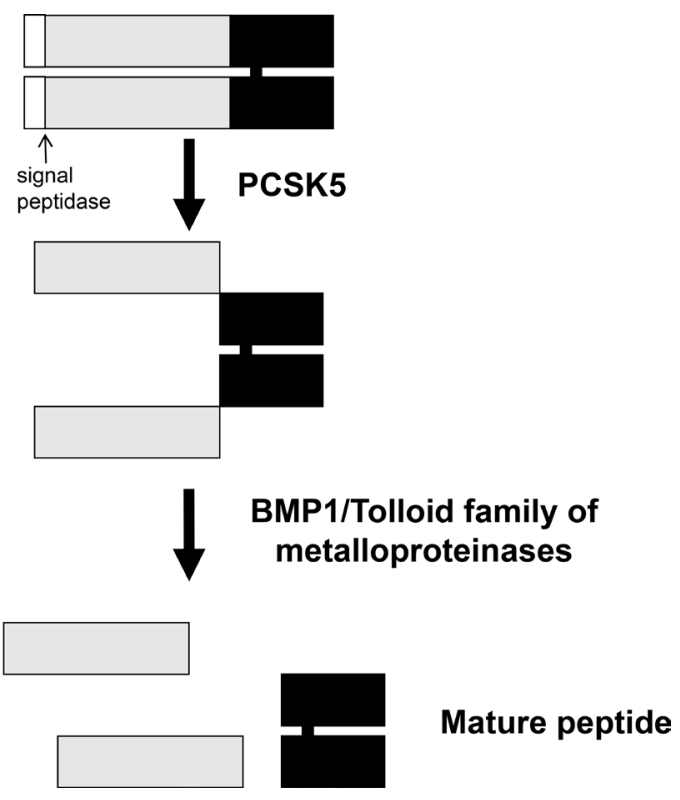

Figure 1: Schematic representation of GDF11 activation by sequential cleavage. GDF11 is cleaved by proprotein convertase subtilisin/kexin 5/ (PCSK5) to form a non-covalent latent complex, which contains N-terminal inhibitory pro-domain and two disulfidelinked carboxyl-terminal active domain. Then, members of BMP1/Tolloid family of metalloproteinases cleave the latent complex at a single specific site to form the mature GDF11 and pro-peptide.

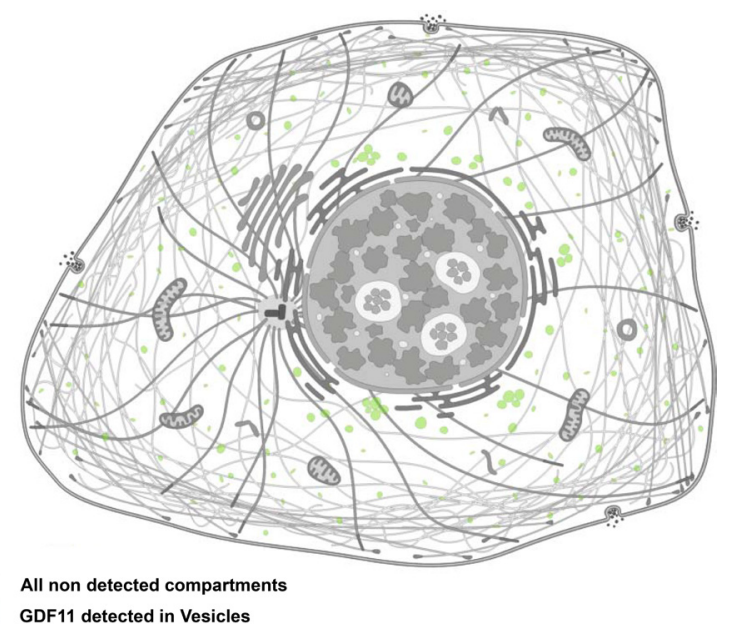

Figure 2: Cellular localization of GDF11. Immunofluorescence staining of GDF11 in CACO-2 and U-2 OS cell lines with antiGDF11 antibody (Sigma-Aldrich, HPA060985; http://www.proteinatlas.org/ENSG00000135414-GDF11/cell). 


\section{Expression and distribution of GDF11}

GDF11 is expressed in embryonic tissues including tailbud, limbs and nervous system as well as adult tissues like spinal cord, olfactory system, dental pulp, skeletal muscle, spleen, pancreas, intestine, kidney, brain, heart and blood $[1,2,9,13,14]$. The mRNA and protein levels of GDF11 vary in different tissues. The seminal vesicle, cerebral cortex, endometrium and cervix express high amounts of GDF11 mRNA, whereas cerebral cortex, adrenal gland, soft tissue, caudate, testis and hippocampus express highest levels of GDF11 protein (Figure 3A and 3B). A recent study shows high GDF11 expression in platelets, thereby suggesting a critical platelet related function while also indicating that serum samples may not be accurate indicators of circulating GDF11 levels [15].

\section{GDF11 signaling pathway}

GDF11 transmits signals through type I and II serine/threonine kinase receptors, similar to other TGF- $\beta$ superfamily members. GDF11 binds first to Activin receptor II (ActRII) including ActRIIA and ActRIIB, and then recruits Activin receptor I (ActRI) including ALK4, ALK5 and ALK7 [16, 17, 18]. GDF11 binding to its receptors activates Smad and non-Smad signaling pathways that represent canonical and non-canonical signaling pathways downstream of TGF- $\beta$ superfamily members. GDF11 activates receptor-Smads (R-Smad) including Smad2/3 and Smad1/5/8. Then, they recruit common Smads (co-Smad, Smad4), migrate into the nucleus and transcribe the target genes [19-21]. Until now, most studies have focused on the Smad2/3 signaling
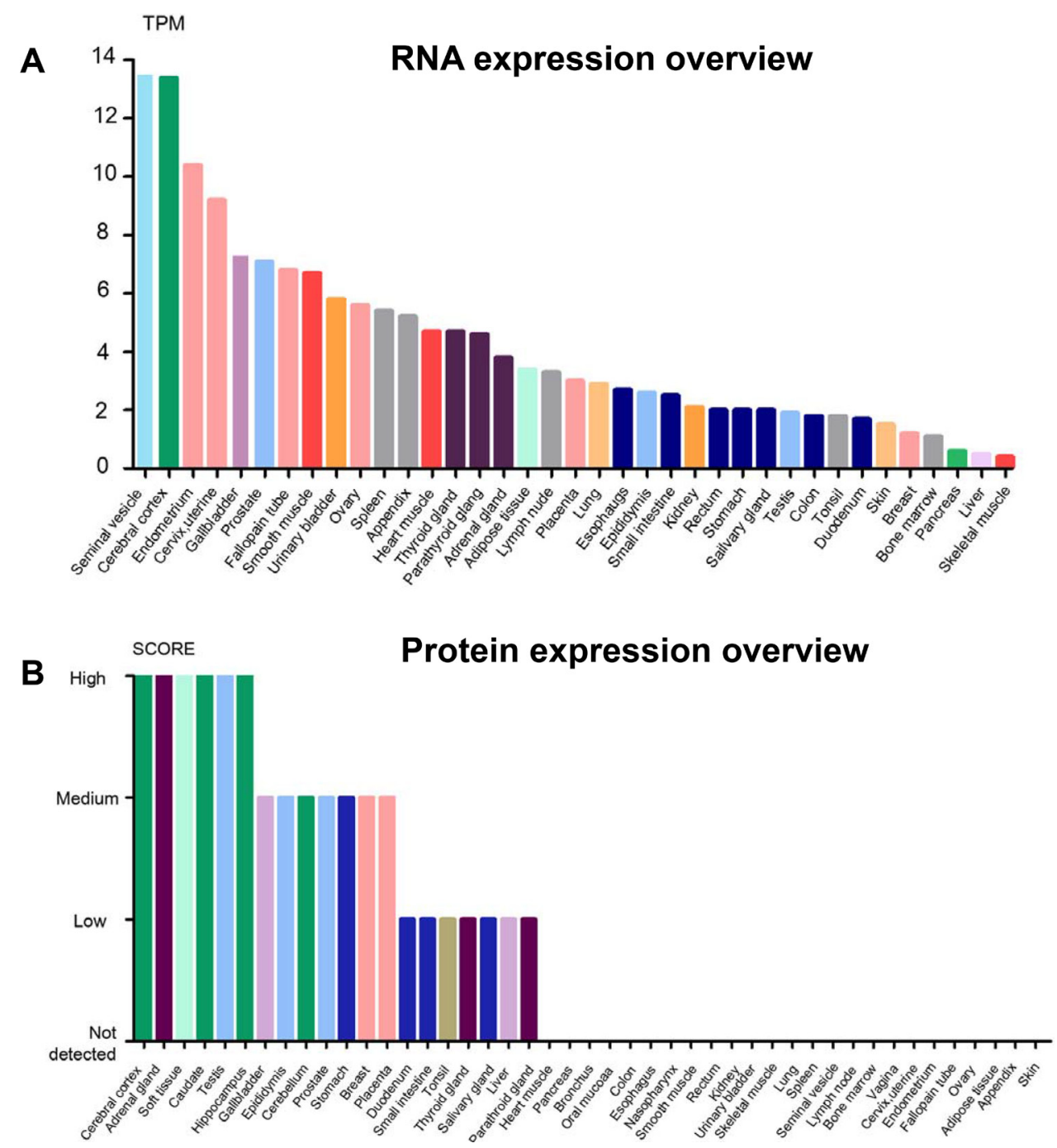

Figure 3: The overview of GDF11 expression in RNA and protein levels. (A) Expression of GDF11 mRNA in human tissues from three different sources, namely, Human Protein Atlas (HPA) RNA-seq data, RNA-seq data from the Genotype-Tissue Expression (GTEx) project and CAGE data from FANTOM5 project. Color-coding is based on tissue groups that are based on tissues with common functional features. (B) GDF11 protein expression data is shown for 44 human tissues. The color-coding is based on tissues with common functional features. Mouse-over function shows protein score for analyzed cell types found in a selected tissue (http://www.proteinatlas. org/ENSG00000135414-GDF11/tissue). 
in regard to GDF11 and only two studies have shown that GDF11 activates Smad1/5/8 in endothelial cells and chick embryos $[22,23]$. Therefore, the relevance of Smad1/5/8 activation by GDF11 in the physiological and pathological processes is not clear. Besides the canonical signal, TGF- $\beta$ superfamily members activate other nonSmad signals like MAP kinases (p38, ERK and JNK), Rho-like GTPase, and phosphatidylinositol-3-kinase/AKT $[24,25]$. GDF11 activates p38 MAPK to regulate the size and function of nucleolus, affects JNK in endothelial cells, as well as has a crosstalk with AMPK, eNOS and NF$\kappa \mathrm{B}[23,26,27]$. GDF11 signaling pathway is negatively regulated by multiple proteins. In the extracellular compartment, WFIKKN1/2, FSTL3 and pro-peptide proteins inhibit GDF11 signal pathway at various points. WFIKKN1/2 proteins, also known as GASP1/2, blocks GDF11 binding to type II receptor through its follistatin and NTR domains, thereby regulating muscle growth and development [28-29]. Follistatin-like 3(FSTL3), which is a secreted glycoprotein, forms inactive complexes with GDF11 and act as an endogenous inhibitor of GDF11 signal [30]. GDF11 propeptide antagonizes GDF11 activity in vitro by forming a latent complex with GDF11 [12]. In the intracellular compartment, GDF11 signaling is modulated by the inhibitory Smads (I-Smad, Smad7) [20]. In addition, histone deacetylases (HDACs), a key transcription regulator, also inhibit GDF11 gene expression to regulate the liver development in zebrafish and the growth of tumor cells $[31,32]$. In vivo and vitro experiments, GDF11 antagonists are used to investigate the function of GDF11. GDF11 signaling pathways are summarized in Figure 4.

\section{Function of GDF11}

\section{GDF11 in development}

The biology of development in animals not only involves embryogenesis, but includes regeneration, asexual reproduction, metamorphosis as well as growth and differentiation of stem cells in the adult organism. Studies have identified the role of GDF11 in spinal cord anterior/posterior patterning and development of bone, skeletal muscle, nervous system, digestive glands and urogenital system in experimental organisms and humans.

\section{GDF11 in anterior posterior patterning of axial} skeleton

The anterior-posterior (AP) also referred as rostral-caudal (head-tail) axis is the most ancient type of embryonic axes [33]. GDF11 is expressed in the primitive streak and tail bud regions in the early developing mouse embryo and regulates anteriorposterior regionalization [8]. GDF11 $1^{+-}$and $\mathrm{GDF} 11^{-/}$ mice show abnormalities in the axial skeleton although

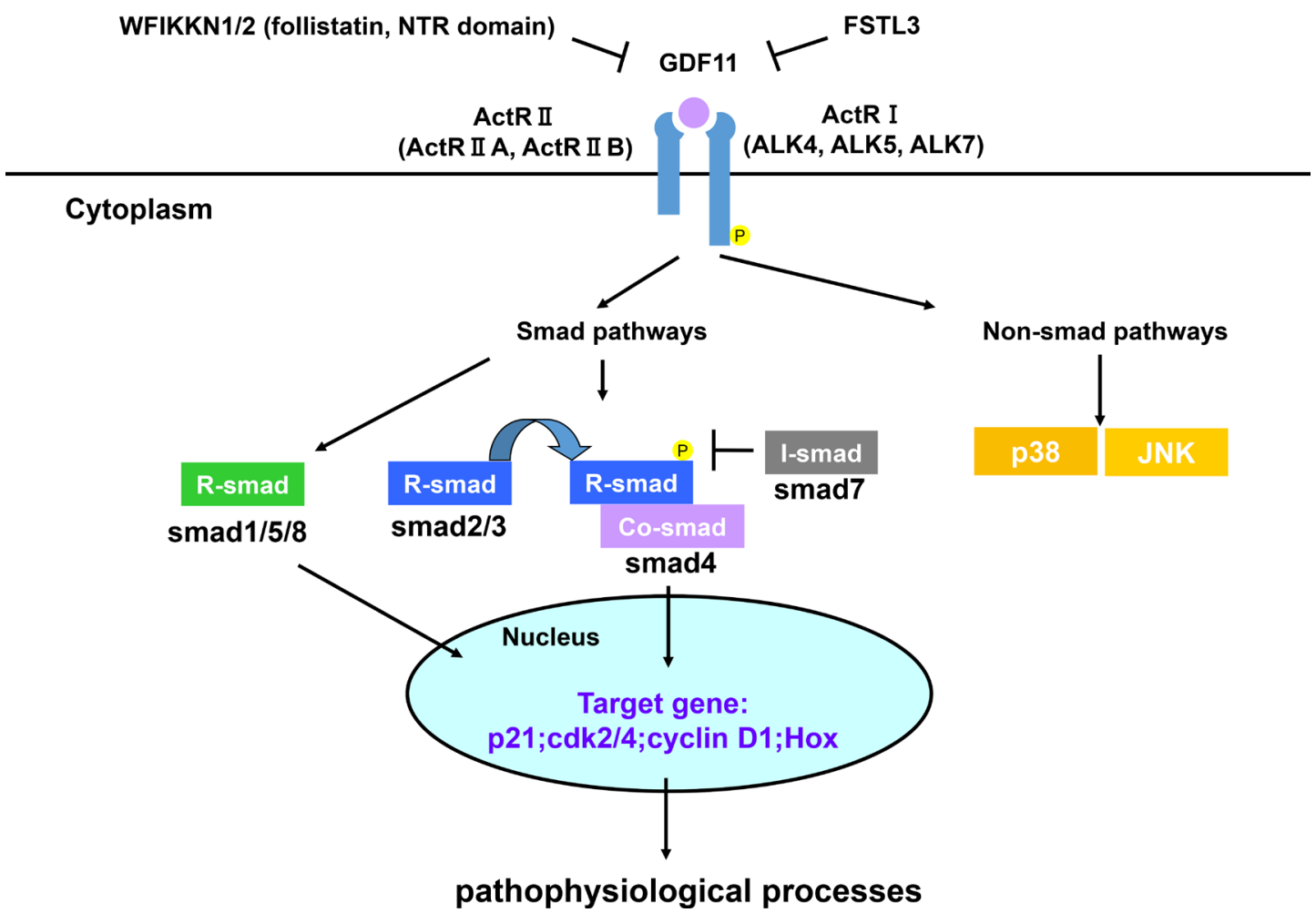

Figure 4: GDF11 signaling pathways. GDF11 activates Smad and non-Smad signals to affect gene expression. The GDF11 signaling pathway is modulated by multiple proteins as negative feedback loops. WFIKKN1/2, FSTL3, and pro-peptide proteins inhibit GDF11 signal pathway at various points in the extracellular compartment. In the intracellular compartment, GDF11 signaling is modulated by the inhibitory Smad proteins (I-Smad, Smad7). 
the phenotype is more severe for GDF $11^{-/-}$mice as they exhibit anterior directed homeotic transformations throughout the axial skeleton and posterior displacement of the hindlimbs. Oh et al. demonstrated that ActRIIA/ ActRIIB compound mutant mice showed abnormal phenotypes similar to GDF $11^{-/-}$mice and that ActRIIA and ActRIIB mediated GDF11-related anterior/ posterior patterning of the axial skeleton by activating Smad2 [34]. The heterozygous $A 1 k 5^{+/-}$mice showed $G D F 11^{-1-}$-like phenotypes in vertebral, kidney and palate development [35]. Mechanistically, GDF11 first binds to ActRIIA and ActRIIB and then recruits type I receptor ALK5 to phosphorylate Smad2, thereby regulating the Hox gene expression in nucleus that influences anterior posterior patterning of axial skeleton $[8,34,35]$.

\section{GDF11 in the bone development}

Osteogenesis (ossification) is the process of laying down new bone material by osteoblasts in bone remodeling. This involves intra-membranous and endochondral ossification. Although the exact mechanism of bone development is unclear, the TGF- $\beta$ superfamily members play a vital role in the process $[36,37]$. Myostatin is a critical regulator of bone development and its deficiency leads to increased bone formation and directly affects proliferation and differentiation of osteoprogenitor cells [38, 39]. Most studies show a negative role for GDF11 in osteogenesis. In postmenopausal Chinese women, GDF11 is an independent negative predictor of total hip and bone mineral density [40]. GDF11 inhibits osteoblastic differentiation of bone marrow mesenchymal stem cells via Smad2/3-Runx2 signaling, thereby inhibiting bone formation and accelerating age-related bone loss in mice [41]. Liu et al. showed that GDF11 led to bone loss and impaired bone regeneration in young adult and aged mice. GDF11 stimulated RANKL-induced osteoclastogenesis through $\mathrm{Smad} 2 / 3$ and c-Fos/Nfatc1, and inhibited osteoblast differentiation by repressing Runnx2 through Smad2/3 [42]. However, Zhang et al. showed that GDF11 was a protective factor for osteoblastogenesis by inhibiting the activity of peroxisome proliferation-activated receptor $\gamma$ (PPAR- $\gamma$ ) [43]. Because of these conflicting results, more studies are necessary to define the role of GDF11 in bone loss-related diseases.

\section{GDF11 in the muscle tissue development}

Myogenesis is characterized by fusion of mononucleate myoblasts to form multinucleated myotubes, especially in embryonic development. GDF8, a secreted protein that is highly related to GDF11, is a known regulator to inhibit skeletal muscle development [44]. There are more and more researches on the role of GDF11 in the development of muscle tissue. It is reported that GDF11 inhibited muscle development and differentiation of myogenic cell lineages in chick embryos [13]. L6E9 myoblasts that lack endogenous myostatin, but express GDF11, activins, ActRIIs and follistatin have been used as in vitro models to identify regulators of muscle fiber size. Differentiation of L6E9 myoblasts showed decreased GDF11 level suggesting its role in muscle fiber formation [45]. Jeanplong et al. directly demonstrated GDF11 regulated growth of skeletal muscles through inhibiting myoblast differentiation. They found the mRNA expression of GDF11 was increased in gastrocnemius muscles at a period of rapid postnatal muscle growth and in gastrocnemius muscles of myostatin knockout mice. In addition, $\mathrm{C}_{2} \mathrm{C}_{12}$ myoblasts and myoblasts isolated from myostatin knockout mice were inhibited by recombinant GDF11 treatment [46]. Egerman et al. showed that GDF11 inhibited myoblast differentiation and muscle regeneration, thereby decreasing the number of myotubes [6]. GDF11 induced myotube atrophy by activating $\operatorname{Smad} 2 / 3$ and its overexpression led to skeletal and cardiac muscle atrophy [47]. The inhibitory function of GDF11 in skeletal muscle development was also demonstrated by GDF11 antagonists such as follistatin and GASP-2. Follistatin overexpression increased muscle weight and induced muscle hypertrophy in control as well as Myostatin-knockout mice, possibly by promoting satellite cell proliferation [48]. GASP-2, which is an inhibitor of both GDF11 and myostatin increased proliferation and differentiation of $\mathrm{C}_{2} \mathrm{C}_{12}$ myoblasts [49]. However, Sinha and others showed that GDF11 rejuvenated muscle fibers of injured old mice by increasing number of multinucleated myotubes, improving other muscle features, and restoring genomic integrity in aged muscle satellite cells [4]. Overall, most researches demonstrated GDF11 can inhibit skeletal muscle development similar to myostatin and is antagonized by factors such as follistatin and GASP-2.

\section{GDF11 in the nervous system development}

GDF11 is also involved in olfactory neurogenesis and optic nerve development. GDF11 and its receptors are expressed by neurons in the olfactory epithelium (OE) and their progenitors. GDF11 plays a vital role in the negative autoregulation of neurogenesis in the $\mathrm{OE}$ by inducing $\mathrm{p} 27^{\mathrm{Kip} 1}$ and the reversible cell cycle arrest in progenitors [50]. OE neurogenesis is stimulated in GDF11-null mice, whereas mice with mutant GDF11 pro-domain or follistatin knockout mice dramatically decrease neurogenesis $[12,51]$. The antineurogenic activity of GDF11 is antagonized by Foxg1, a winged-helix transcription factor, which promotes olfactory neurogenesis [52]. GDF11 and its receptor ActRIIB are expressed in the Xenopus retina and the developing mouse ganglion cell layer [1, 53]. Apart from its negative role in OE development, GDF11 also negatively regulates neuronal numbers in the retina by governing the temporal windows during which multipotent progenitors retain competence to produce distinct neural progeny independent of $\mathrm{p} 27^{\mathrm{Kip} 1}$ levels and the effects of proliferation [54]. Santos et al. reported that absence of GDF11 increased the number of retinal 
ganglion cells (RGCs) and reduced GDF11 levels restored retinal development in visual system homeobox 2 (Vsx2) deficient mice [55]. Because of its function and expression pattern in neurogenesis of optic nerve, GDF11 is a promising candidate gene in familial cavitary optic disk anomalies [56]. In addition to olfactory neurogenesis and optic nerve development, GDF11 is involved in spinal cord neurogenesis. In the developing spinal cord, GDF11 is secreted by newly born neurons and promotes cell cycle exit, decreases proliferation, changes differentiation potential and facilitates the temporal progression of neurogenesis [57]. On the other hand, Katisimpardi et al. demonstrated that GDF11 increased neurogenesis in aged mice. Old mice that were treated with daily doses of recombinant GDF11 increased Sox $2^{+}$neural stem cell populations in the brain indicating that GDF11 restored neurogenesis [3]. Therefore, the positive or negative role of GDF11 in neurogenesis may depend on different tissues and temporal contexts in an organism.

\section{GDF11 in the digestive glands development}

GDF11 is involved the development of liver and the islets. Histone deacetylases (HDACs) has a vital role in zebrafish liver development by regulating GDF11 expression [31]. HDACs are required for liver and exocrine pancreas development in zebrafish. Overexpression of $H D A C 3$ increases liver size, whereas overexpression of GDF11 generates a small liver phenotype although knockdown of GDF11 alone showed no liver phenotype [31]. Meanwhile, the small liver defect in GDF11 overexpressed embryos was neutralized by simultaneous $H D A C 3$ overexpression. GDF11 overexpression produced a small liver, possibly by suppressing hepatocyte proliferation. HDAC3 regulates zebrafish liver growth by inhibiting GDF11 [31]. In the mouse, GDF11 is expressed in the embryonic pancreatic epithelium at embryonic day E12-E14 [58, 59]. GDF11 ${ }^{-/}$ embryos show malformation of the stomach, spleen and pancreas. Mice deficient for GDF11 disrupt islet development and increase $\mathrm{NGN}^{+}$cell numbers, thereby indicating that GDF11 negatively regulates $\mathrm{NGN}^{+}$islet progenitor cell numbers. Moreover, GDF11 promotes pancreatic beta-cell differentiation by Smad2 in parallel to the Notch pathway [58]. In GDF $11^{-/}$animals, Nkx6.1 cells, which are required for development of beta cells, cannot express MafA, an insulin gene transcription factor that promotes beta cell maturation [60]. Dichmann et al. showed that pancreas size was two-fold reduced in GDF $11^{-/-}$mouse embryos with a hypoplasia of the exocrine compartment and increased NGN3+ endocrine precursor cells indicating the significant role of GDF11 in pancreatic development [59].

\section{GDF11 in the urogenital system development}

Kidney development follows stepwise progression of the pronephros, the mesonephros and the metanephros phases. The development process of ureteric bud, known as the metanephrogenic diverticulum originates from outgrowth of the end part of Wolffian duct, which invades into metanephric kidney induced by metanephric mesenchyme. During kidney development, GDF11 is essential for outgrowth and positioning of the ureteric bud, which is the inducer of metanephric mesenchyme [61]. GDF11 is expressed in the Wolffian duct and the metanephric mesenchyme. Mice carrying a targeted deletion of GDF11 show bilateral or unilateral agenesis or hypoplasia of kidneys. In mesenchyme cells, GDF11 increases the expression of Glial cell line-derived neurotrophic factor (GDNF), which directs the outgrowth of a ureteric bud from the Wolffian duct $[61,62]$.

\section{GDF11 in erythropoiesis}

Erythropoiesis is the process of generating new erythrocytes and ineffective erythropoiesis is involved in anemia [63-65]. Previous studies have demonstrated that GDF11 has a critical role in normal erythropoiesis as well as the pathology of $\beta$-thalassemia, myelodysplastic syndrome (MDS), and erythropoietin-resistant anemia in hemodialysis (HD) patients [20,66-68]. During the normal process of erythropoiesis, GDF11 is mainly expressed in immature erythroid progenitors and is necessary for their survival and to inhibit terminal differentiation [69]. In anemia, GDF11 promotes proliferation of erythroid precursors and inhibits erythroid maturation [70, 71].

Ineffective erythropoiesis and iron-restricted anemia can be treated by GDF11 traps sotatercept ACE-011 and ACE-536 [70, 71]. ACE-011 and its mouse version RAP011, which is a ligand trap made up of the extracellular domain of ActRIIA linked to the human IgG1 Fc domain improves hematological parameters by decreasing ineffective erythropoiesis, iron overload and red blood cell-associated hemoglobin precipitates in thalassemic mice. GDF11 is overexpressed in $\beta$-thalassemia and inhibits terminal erythropoiesis [70]. ACE-536 and its mouse version RAP-536 are ligand-trapping fusion proteins containing the extracellular domain of human activin receptor type IIB modified to reduce activin binding [71]. ACE-536 increased the number of red blood cells, hemoglobin concentration and hematocrit values by promoting maturation of late-stage erythroblasts. GDF11 inhibits late-stage erythroid differentiation by activating Smad2/3. In myelodysplastic syndrome (MDS) patients, high GDF11 levels in high-risk MDS patients was accompanied by low RBC numbers, hemoglobin concentration and hematocrit values implying that GDF11 negatively correlated with late erythropoiesis [72]. In MDS erythropoiesis, GDF11 is probably involved in increased iron overload (IO) that contributes to the pathological mechanism [73]. Therefore, GDF11 and GDF11 traps are novel therapeutics in the field of aberrant iron metabolism and erythropoietic disorders. 


\section{Table 1: Two different viewpoints of GDF11 in aging-related cardiovascular diseases and muscle}

dysfunction

\begin{tabular}{|c|c|c|}
\hline Viewpoints & Findings & Ref. \\
\hline \multirow{6}{*}{$\begin{array}{l}\text { The positive function of GDF11 in } \\
\text { aging-related cardiovascular diseases } \\
\text { and muscle dysfunction }\end{array}$} & GDF11 levels decline with age. & {$[19][43][77-81]$} \\
\hline & GDF11 reverses age-related cardiac hypertropy. & {$[2][19][77-81]$} \\
\hline & GDF11 improves vascular and neurogenic function in aging mouse brain. & [3] [19] [78-81] \\
\hline & GDF11 restores age-related skeletal muscle dysfunction in aging mouse. & [4] [19] [78-81] \\
\hline & $\begin{array}{l}\text { GDF11 decreases the risk of cardiovascular events and death in patients with stable ischaemic heart disease, } \\
\text { protects against endothelial injury and reduces atherosclerotic lesion formation in apolipoprotein E-Null mice. }\end{array}$ & [27] [94] \\
\hline & GDF11 serves as a novel predictor of mammalian life span. & {$[82]$} \\
\hline \multirow{5}{*}{$\begin{array}{l}\text { The negative or no function of GDF11 } \\
\text { in aging-related cardiovascular } \\
\text { diseases and muscle dysfunction }\end{array}$} & GDF11 serum levels increase, unchange or can not be detected with age and disease. & {$[5,6][40][84,85]$} \\
\hline & GDF11 does not rescue aging-raleted pathological hypertrophy. & {$[5][85]$} \\
\hline & GDF11 has a harmful effect or no significant effect on muscle function & {$[6][85-87]$} \\
\hline & Elevated GDF11 is a risk factor for age-related frailty and disease in humans. & {$[84][88]$} \\
\hline & GDF11 administration does not extend lifespan in a mouse model of premature aging. & {$[89]$} \\
\hline
\end{tabular}

\section{GDF11 in aging and cardiovascular disease}

Loffredo et al. reported that GDF11 reversed agerelated cardiac hypertrophy [2]. Since then, GDF11 became a prominent cytokine in rejuvenation biology. However, a series of studies reported contradictory findings shown in Table 1. This has led to a debate on the role of GDF11 in aging and cardiovascular diseases.

The process of aging involves debilitating loss of tissue and cellular functions that result in degenerative pathologies. The most common features of aging include cardiac hypertrophy, decline of vascular and neurogenic function, muscle dysfunction, osteoporosis and enhanced risk of cardiovascular pathology and death. Studies have demonstrated that the mTOR inhibitor rapamycin and caloric restriction can delay aging $[74,75,76]$. Several studies showed that GDF11 reversed aging and agingrelated dysfunction in muscle, nerve, cardiovascular system. While serum GDF11 levels decreased upon aging, supplementation of GDF11 rejuvenated the old mice, thereby suggesting that GDF11 was a novel predictor of mammalian life span $[2,3,19,43,77-82]$. GDF11 also improved tubular regeneration after acute kidney injury in elderly mice [83]. On the contrary, many studies showed that GDF11 had no significant effect on the process of aging and could not rescue aging-related pathological cardiac hypertrophy; in fact GDF11 inhibited skeletal muscle regeneration, led to bone loss in both young and aged mice and its serum levels increased or remained unchanged with age $[5,6,40,42,84,85]$. Treatment with rGDF11 did not improve the dystrophic muscle pathology of mdx mutant mice, which are a model for the hereditary muscular dystrophy and it is lack of evidence for GDF11 as a rejuvenator of aged skeletal muscle satellite cells $[86,87]$. Schafer et al reported elevated circulating GDF11 levels increased age-related frailty and disease in humans $[84,88]$. Moreover, GDF11 administration did not extend lifespan of prematurely aged mice [89].
Similarly, GDF11 has a dual role in diabetes and cardiovascular diseases. Adela et al. demonstrated decreased plasma GDF11 levels in Type 2 diabetes mellitus (T2DM), T2DM with hypertension \& coronary artery disease and $\mathrm{T} 2 \mathrm{DM}$ with coronary artery disease in Indian patients [90]. However, Fadini et al. showed higher plasma GDF11 concentration in T2DM and T2DM with cardiovascular disease (CVD) patients [91]. Elevated circulating GDF11 levels increased prevalance of diabetes, prior cardiac abnormalities, frailty, risk of postoperative complications and re-hospitalization. [84, 88]. Mei et al. and Li et al. concluded that adenovirus vector transfected GDF11 and recombinant GDF11 reduced atherosclerosis in apoliprotein $\mathrm{E}^{-/}$mice and attenuated development of T2DM by improving islet $\beta$ cell function and survival [27, 92]. However, in vitro experiment, Jing et al. showed that supplementation of GDF11 did not ameliorate the palmitate-induced insulin resistance in $\mathrm{C} 2 \mathrm{C} 12$ myotubes [93]. In the field of cardiovascular diseases, some studies suggest that GDF11 decreases the risk of cardiovascular events and death in patients with stable ischaemic heart disease and improves agingrelated cardiac hypertrophy $[2,94]$. Ultrasound-targeted microbubble destruction-mediated delivery of the GDF11 plasmid to the aged heart enhanced myocardial regeneration after ischemia-reperfusion injury [95]. However, other studies concluded that GDF11 was associated with comorbidity, frailty, and post-operative outcomes in cardiovascular disease and that GDF11 supplementation did not rescue aging-related pathological hypertrophy [5, 84, 85]. In addition, the effects of GDF11 on endothelial cells are controversial as shown in Table 2. Katsimpardi et al. showed that GDF11 increased the proliferation of primary brain capillary endothelial cells by $22.9 \%$ for 6 day treatment in 5\% FBS culture media containing VEGF and EGF [3]. However, Finkenzeller et al. demonstrated that GDF11 did not affect cell 
Table 2: The effect of GDF11 on cell viability, cell proliferation and cell migration in different endothelial cells

\begin{tabular}{|c|c|c|c|c|c|c|}
\hline Cell type & culture condition & GDF11 (concentration/time) & cell viability & cell proliferation & cell migration & Ref. \\
\hline brain capillary endothelial cells & 5\% FBS (VEGF;EGF) & $40 \mathrm{ng} / \mathrm{mL} 6$ days & & + & & {$[3]$} \\
\hline endothelial progenitor cells & $10 \%$ FBS & $40 \mathrm{ng} / \mathrm{mL} 3$ days & & none & & [96] \\
\hline endothelial progenitor cells & $10 \% \mathrm{FBS}$ & $40 \mathrm{ng} / \mathrm{mL} 1 \mathrm{~h}$ & & & & [96] \\
\hline endothelial progenitor cells & Without FBS & $40 \mathrm{ng} / \mathrm{mL} 1$ day & & & + & [96] \\
\hline human umbilical endothelial cells & $10 \% \mathrm{FBS}$ & $50 \mathrm{ng} / \mathrm{mL}$ & none & none & none & {$[23]$} \\
\hline rat aortic endothelial cells & $10 \% \mathrm{FBS}$ & $50 \mathrm{ng} / \mathrm{mL}$ & none & none & none & {$[23]$} \\
\hline human umbilical endothelial cells & Without FBS & $50 \mathrm{ng} / \mathrm{mL}$ & + & & & [23] \\
\hline mice aortic endothelial cells & unknown & $50 \mathrm{ng} / \mathrm{mL} 1$ or 3 days & & none & & {$[27]$} \\
\hline mice aortic endothelial cells & unknown & $50 \mathrm{ng} / \mathrm{mL} 5$ days & & + & & {$[27]$} \\
\hline mice aortic endothelial cells & unknown & unknown & & & none & {$[27]$} \\
\hline
\end{tabular}

+:promotion; none:no significant effect.

adherence, proliferation, and apoptosis of endothelial progenitor cells isolated from human peripheral blood in $10 \%$ FBS culture media, but increased cell migration in culture media without FBS [96]. Zhang et al. also showed that GDF11 did not affect cell viability, cell migration and cell proliferation of human umbilical endothelial cell and rat aortic endothelial cell in 10\% FBS culture media [23]. Mei et al. concluded cell migration can not be affected by GDF11 in mice aortic endothelial cells. GDF11 did not increase cell proliferation until 5 day treatment [27].

Therefore, there are contradictory views on the role of GDF11 in the field of aging, cardiovascular diseases, diabetes, muscle dysfunction and endothelial cell function. These may be caused by many variables in different studies such as the source of the mice, sex, recombinant GDF11 active domain, different GDF11 detection methods, the action time and concentration of GDF11, types of muscle injury, genetic background and others.

\section{GDF11 in cancer and other diseases}

TGF- $\beta$ family members and their receptors play a major regulatory role in cancer. In normal cells and early carcinomas, TGF- $\beta$ signaling pathways exert tumor suppressor effects and in advanced tumors TGF- $\beta$ signaling promotes cancer metastasis [97-99]. According the Human Protein Atlas database, GDF11 is involved in the breast, colorectal, liver and pancreatic cancers (Figure 5). Colorectal cancer patients with high GDF11 expressing

\section{Human protein atlas}

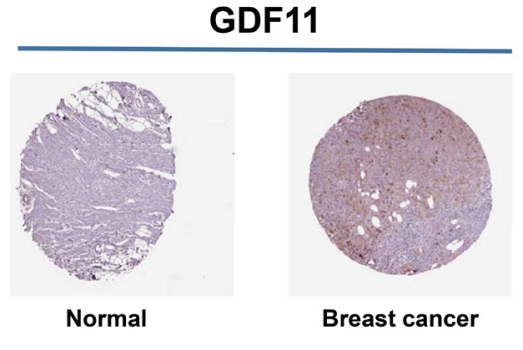

GDF11

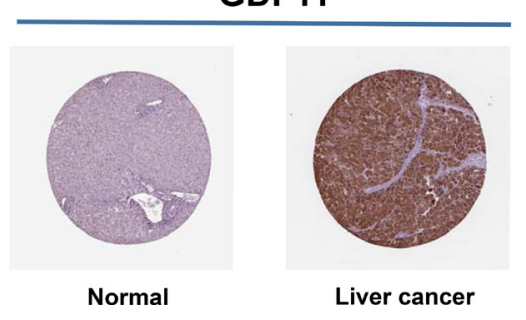

GDF11

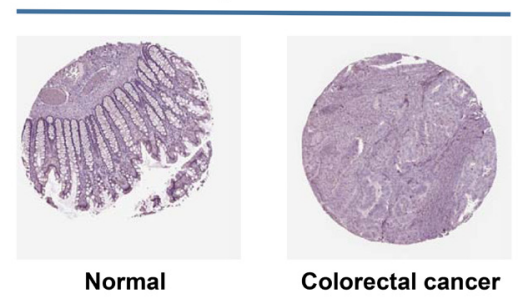

GDF11

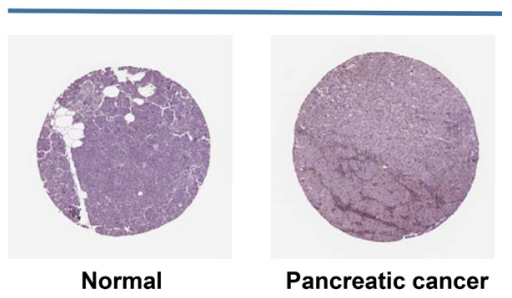

Figure 5: Expression of GDF11 in human cancers. GDF11 expression increases in breast, colorectal, liver and pancreatic cancers. Representative images show GDF11 immunohistochemical staining of histological sections from normal and cancer tissues (Human Protein Atlas). Brown staining indicates GDF11 staining, whereas hematoxylin counterstain enables visualization of microscopical features (http:// www.proteinatlas.org/ENSG00000135414-GDF11/cancer). 
tumors show a high frequency of lymph node metastasis and poor survival [100]. However, histone deacetylase (HDAC) inhibitor trichostatin A suppressed tumor growth by activating GDF11 in vitro [32]. The contradictory results may be caused by the dual role of TGF- $\beta$ in the different stages of cancer. GDF11 is also reported to participate in breast cancer and leiomyoma uteri [101, 102]. However, GDF11 has not been investigated in other cancers and further indepth studies are needed to clarify the mechanism and function of GDF11 in cancers. Besides, GDF11 has a role in dental restoration, Epstein-Barr virus infection, primary dysmenorrhea and endometrium decidualization [103-107].

\section{CONCLUSIONS}

In this review, we described the GDF11 signaling pathway and the role of GDF11 in physiological and pathological processes in the areas of organ development, erythropoiesis, aging, cardiovascular disease, diabetes mellitus, cancer and other diseases.GDF11 is involved in anterior-posterior pattering of axis skeleton, digestive gland development and urogenital system development. Also, most studies show that GDF11 negatively regulates osteogenesis, skeletal muscle development, olfactory and optic neurogenesis and erythroid maturation (late erythropoeisis). However, the role of GDF11 in aging and cardiovascular diseases is controversial and not comprehensively studied. Moreover, its function in most cancers and hematological disorders has also not been studied in detail. Nevertheless, studies so far demonstrate that GDF11 signaling has important implications in human development and disease with potential clinical applications in the future.

\section{ACKNOWLEDGMENTS AND FUNDING}

This work was supported by the Science and Technology Research Program of Chongqing Education Commission (KJ1725391 and KJ1710238) and Natural Science Research Program of Chongqing Three Gorges Medical College (2016xmpxz02).

\section{CONFLICTS OF INTEREST}

The authors declare no conflicts of interest.

\section{REFERENCES}

1. Nakashima M, Toyono T, Akamine A, Joyner A. Expression of growth/differentiation factor 11, a new member of the BMP/TGFbeta superfamily during mouse embryogenesis. Mech Dev. 1999; 80:185-189.

2. Loffredo FS, Steinhauser ML, Jay SM, Gannon J, Pancoast JR, Yalamanchi P, Sinha M, Dall'Osso C, Khong D, Shadrach JL, Miller CM, Singer BS, Stewart A, et al. Growth differentiation factor 11 is a circulating factor that reverses age-related cardiac hypertrophy. Cell. 2013; 153:828-839.

3. Katsimpardi L, Litterman NK, Schein PA, Miller CM, Loffredo FS, Wojtkiewicz GR, Chen JW, Lee RT, Wagers AJ, Rubin LL. Vascular and neurogenic rejuvenation of the aging mouse brain by young systemic factors. Science. 2014; 344:630-634.

4. Sinha M, Jang YC, Oh J, Khong D, Wu EY, Manohar R, Miller C, Regalado SG, Loffredo FS, Pancoast JR, Hirshman MF, Lebowitz J, Shadrach JL, et al. Restoring systemic GDF11 levels reverses age-related dysfunction in mouse skeletal muscle. Science.2014; 344:649-652.

5. Smith SC, Zhang X, Zhang X, Gross P, Starosta T, Mohsin S, Franti M, Gupta P, Hayes D, Myzithras M, Kahn J, Tanner J, Weldon SM, et al. GDF11 Does Not Rescue Aging-Related Pathological Hypertrophy. Circ Res. 2015; 117:926-932.

6. Egerman MA, Cadena SM, Gilbert JA, Meyer A, Nelson HN, Swalley SE, Mallozzi C, Jacobi C, Jennings LL, Clay I, Laurent G, Ma S, Brachat S, et al. GDF11 Increases with Age and Inhibits Skeletal Muscle Regeneration. Cell Metab. 2015; 22:164-174.

7. McPherron AC, Lawler AM, Lee SJ. Regulation of skeletal muscle mass in mice by a new TGF-beta superfamily member. Nature. 1997; 387:83-90.

8. McPherron AC, Lawler AM, Lee SJ. Regulation of anterior/ posterior patterning of the axial skeleton by growth/ differentiation factor 11. Nat Genet. 1999; 22:260-264.

9. Gamer LW, Wolfman NM, Celeste AJ, Hattersley G, Hewick R, Rosen V. A novel BMP expressed in developing mouse limb, spinal cord, and tail bud is a potent mesoderm inducer in Xenopus embryos. Dev Biol.1999; 208:222-232.

10. Essalmani R, Zaid A, Marcinkiewicz J, Chamberland A, Pasquato A, Seidah NG, Prat A. In vivo functions of the proprotein convertase PC5/6 during mouse development: Gdf11 is a likely substrate. Proc Natl Acad Sci USA. 2008; 105:5750-5755.

11. Tsuda T, Iwai N, Deguchi E, Kimura O, Ono S, Furukawa T, Sasaki Y, Fumino S, Kubota Y. PCSK5 and GDF11 expression in the hindgut region of mouse embryos with anorectal malformations. Eur J Pediatr Surg. 2011; 21:238-241.

12. Ge G, Hopkins DR, Ho WB, Greenspan DS. GDF11 forms a bone morphogenetic protein 1-activated latent complex that can modulate nerve growth factor-induced differentiation of PC12 cells. Mol Cell Biol. 2005; 25:5846-5858.

13. Gamer LW, Cox KA, Small C, Rosen V. Gdf11 is a negative regulator of chondrogenesis and myogenesis in the developing chick limb. Dev Biol. 2001; 229:407-420.

14. McPherron AC. Metabolic functions of myostatin and GDF11. Immunol Endocr Metab Agents Med Chem. 2010; 10:217-231.

15. Bueno JL, Ynigo M, de Miguel C, Gonzalo-Daganzo RM, Richart A, Vilches C, Regidor C, García-Marco JA, Flores- 
Ballester E, Cabrera JR. Growth differentiation factor 11 (GDF11) - a promising anti-ageing factor - is highly concentrated in platelets. Vox Sang. 2016; 111:434-436.

16. McNally EM. Questions and Answers About Myostatin, GDF11, and the Aging Heart.Circ Res. 2016; 118:6-8.

17. Hannan NR, Jamshidi P, Pera MF, Wolvetang EJ. BMP-11 and myostatin support undifferentiated growth of human embryonic stem cells in feeder-free cultures. Cloning Stem Cells. 2009; 11:427-435

18. Tsuchida K, Nakatani M, Uezumi A, Murakami T, Cui X. Signal transduction pathway through activin receptors as a therapeutic target of musculoskeletal diseases and cancer. Endocr J. 2008; 55:11-21.

19. Camici GG, Savarese G, Akhmedov A, Lüscher TF. Molecular mechanism of endothelial and vascular aging: implications for cardiovascular disease. Eur Heart J. 2015; 36:3392-403.

20. Rochette L, Zeller M, Cottin Y, Vergely C. Growth and differentiation factor 11 (GDF11): Functions in the regulation of erythropoiesis and cardiac regeneration. Pharmacol Ther. 2015; 156:26-33.

21. Brun CE, Rudnicki MA. GDF11 and the Mythical Fountain of Youth. Cell Metab. 2015; 22:54-56.

22. Liu JP. The function of growth/differentiation factor 11 (Gdf11) in rostrocaudal patterning of the developing spinal cord. Development. 2006; 133:2865-2874.

23. Zhang YH, Cheng F, Du XT, Gao JL, Xiao XL, Li N, Li SL, Dong de L. GDF11/BMP11 activates both smad1/5/8 and smad2/3 signals but shows no significant effect on proliferation and migration of human umbilical vein endothelial cells. Oncotarget. 2016; 7:12063-12074. https:// doi.org/10.18632/oncotarget.7642.

24. Schmierer B, Hill CS. TGF beta-SMAD signal transduction: molecular specificity and functional flexibility. Nat Rev Mol Cell Biol. 2007; 8:970-982.

25. Zhang YE. Non-Smad pathways in TGF-beta signaling. Cell Res. 2009; 19:128-139.

26. Patel VK, Demontis F. Gdf11/myostatin and aging. Aging(Albany NY).2014; 6:351-352. https://doi. org/10.18632/aging.100666.

27. Mei W, Xiang G, Li Y, Li H, Xiang L, Lu J, Xiang L, Dong J, Liu M. GDF11 Protects against Endothelial Injury and Reduces Atherosclerotic Lesion Formation in Apolipoprotein E-Null Mice. Mol Ther. 2016; 24:1926-1938.

28. Szláma G, Kondás K, Trexler M, Patthy L. WFIKKN1 and WFIKKN2 bind growth factors TGF $\beta 1$, BMP2 and BMP4 but do not inhibit their signalling activity. FEBS J. 2010; 277:5040-5050.

29. Lee YS, Lee SJ. Regulation of GDF-11 and myostatin activity by GASP-1 and GASP-2. Proc Natl Acad Sci USA. 2013; 110:E3713-3722.

30. Robertson RD, Mukherjee A. Synexpression group analyses identify new functions of FSTL3, a TGF $\beta$ ligand inhibitor. Biochem Biophys Res Commun. 2012; 427:568-573.
31. Farooq M, SuLochana KN, Pan X, To J, Sheng D, Gong Z, Ge R. Histone deacetylase3(HDAC3) is specifically required for liver development in zebrafish. Developmental biology. 2008; 317:336-353.

32. Zhang X, Wharton W, Yuan Z, Tsai SC, Olashaw N, Seto E. Activation of the growth-differentiation factor 11 gene by the histone deacetylase (HDAC) inhibitor trichostatin A and repression by HDAC3. Mol Cell Biol. 2004; 24:5106-5118.

33. Kimelman D, Martin BL. Anterior-posterior patterning in early development: three strategies. Wiley Interdiscip Rev Dev Biol. 2012; 1:253-266.

34. Oh SP, Yeo CY, Lee Y, Schrewe H, Whitman M, Li E. Activin type IIA and IIB receptors mediate Gdf11 signaling in axial vertebral patterning. Genes Dev. 2002; 16:2749-2754.

35. Andersson $\mathrm{O}$, Reissmann E, Ibáñez CF. Growth differentiation factor 11 signals through the transforming growth factor-beta receptor ALK5 to regionalize the anterior-posterior axis. EMBO Rep. 2006; 7:831-837.

36. Oka K, Oka S, Sasaki T, Ito Y, Bringas P Jr, Nonaka K, Chai $\mathrm{Y}$. The role of TGF-beta signaling in regulating chondrogenesis and osteogenesis during mandibular development. Dev Biol. 2007; 303:391-404.

37. Chen G, Deng C, Li YP. TGF- $\beta$ and BMP signaling in osteoblast differentiation and bone formation. Int J Biol Sci. 2012; 8:272-288.

38. Elkasrawy MN, Hamrick MW. Myostatin (GDF-8) as a key factor linking muscle mass and bone structure. J Musculoskelet Neuronal Interact. 2010; 10:56-63.

39. Hamrick MW, Shi X, Zhang W, Pennington C, Thakore H, Haque M, Kang B, Isales CM, Fulzele S, Wenger KH. Loss of myostatin (GDF8) function increases osteogenic differentiation of bone marrow-derived mesenchymal stem cells but the osteogenic effect is ablated with unloading. Bone. 2007; 40:1544-1553.

40. Chen Y, Guo Q, Zhang M, Song S, Quan T, Zhao T, Li H, Guo L, Jiang T, Wang G. Relationship of serum GDF11 levels with bone mineral density and bone turnover markers in postmenopausal Chinese women. Bone Res. 2016; 4:16012.

41. Lu Q, Tu ML, Li CJ, Zhang L, Jiang TJ, Liu T, Luo XH. GDF11 Inhibits Bone Formation by Activating Smad2/3 in Bone Marrow Mesenchymal Stem Cells. Calcif Tissue Int. 2016; 99:500-509.

42. Liu W, Zhou L, Zhou C, Zhang S, Jing J, Xie L, Sun N, Duan X, Jing W, Liang X, Zhao H, Ye L, Chen Q, et al. GDF11 decreases bone mass by stimulating osteoclastogenesis and inhibiting osteoblast and inhibiting osteoblast differentiation. Nat Commun. 2016; 7:12794.

43. Zhang Y, Shao J, Wang Z, Yang T, Liu S, Liu Y, Fan X, Ye W. Growth differentiation factor 11 is a protective factor for osteoblastogenesis by targeting PPARgamma. Gene. 2015; 557:209-214.

44. Thomas M, Langley B, Berry C, Sharma M, Kirk S, Bass J, Kambadur R. Myostatin, a negative regulator of muscle growth, functions by inhibiting myoblast proliferation. J Biol Chem. 2000; 275:40235-40243. 
45. Rossi S, Stoppani E, Gobbo M, Caroli A, Fanzani A. L6E9 myoblasts are deficient of myostatin and additional TGF-beta members are candidates to developmentally control their fiber formation. J Biomed Biotechnol. 2010; 2010:326909.

46. Jeanplong F, Falconer SJ, Thomas M, Matthews KG, Oldham JM, Watson T, McMahon CD. Growth and differentiation factor-11 is developmentally regulated in skeletal muscle and inhibits myoblast differentiation. Molecular and Integrative Physiology. 2012; 2:127-138.

47. Hammers DW, Merscham-Banda M, Hsiao JY, Engst S, Hartman JJ, Sweeney HL. Supraphysiological levels of GDF11 induce striated muscle atrophy. EMBO Mol Med. 2017; 9:531-544.

48. Gilson H, Schakman O, Kalista S, Lause P, Tsuchida K, Thissen JP. Follistatin induces muscle hypertrophy through satellite cell proliferation and inhibition of both myostatin and activin. Am J Physiol Endocrinol Metab. 2009; 297:E157-164.

49. Luce P, Alexis P, Caroline B, Laetitia M, Patrick P, Véronique $\mathrm{B}$. Enhancement of $\mathrm{C} 2 \mathrm{C} 12$ myoblast proliferation and differentiation by GASP-2, a myostatin inhibitor. Biochem Biophys Rep. 2016; 6:39-46.

50. Wu HH, Ivkovic S, Murray RC, Jaramillo S, Lyons KM, Johnson JE, Calof AL. Autoregulation of neurogenesis by GDF11. Neuron. 2003; 37:197-207.

51. Gokoffski KK, Wu HH, Beites CL, Kim J, Kim EJ, Matzuk MM, Johnson JE, Lander AD, Calof AL. Activin and GDF11 collaborate in feedback control of neuroepithelial stem cell proliferation and fate. Development. 2011; 138:4131-4142.

52. Kawauchi S, Kim J, Santos R, Wu HH, Lander AD, Calof AL. Foxg1 promotes olfactory neurogenesis by antagonizing Gdf11. Development. 2009; 136:1453-1464.

53. Hocking JC, Hehr CL, Chang RY, Johnston J, McFarlane S. TGFbeta ligands promote the initiation of retinal ganglion cell dendrites in vitro and in vivo. Mol Cell Neurosci. 2008; 37:247-260.

54. Kim J, Wu HH, Lander AD, Lyons KM, Matzuk MM, Calof AL. GDF11 controls the timing of progenitor cell competence in developing retina. Science. 2005; 308:1927-1930.

55. Santos R, Wu J, Hamilton JA, Pinter R, Hindges R, Calof AL. Restoration of retinal development in Vsx2 deficient mice by reduction of Gdf11 levels. Adv Exp Med Biol. 2012; 723:671-677.

56. Fingert JH, Honkanen RA, Shankar SP, Affatigato LM, Ehlinger MA, Moore MD, Jampol LM, Sheffield VC, Stone EM, Alward WL. Familial cavitary optic disk anomalies: identification of a novel genetic locus. Am J Ophthalmol. 2007; 143:795-800.

57. Shi Y, Liu JP. Gdf11 facilitates temporal progression of neurogenesis in the developing spinal cord. J Neurosci. 2011; 31:883-893.

58. Harmon EB, Apelqvist AA, Smart NG, Gu X, Osborne DH, Kim SK. GDF11 modulates NGN3+ islet progenitor cell number and promotes beta-cell differentiation in pancreas development. Development. 2004; 131:6163-6174.

59. Dichmann DS, Yassin H, Serup P. Analysis of pancreatic endocrine development in GDF11-deficient mice. Dev Dyn. 2006; 235:3016-3025.

60. Smart NG, Apelqvist AA, Gu X, Harmon EB, Topper JN, MacDonald RJ, Kim SK. Conditional expression of Smad7 in pancreatic beta cells disrupts TGF-beta signaling and induces reversible diabetes mellitus. PLoS Biol. 2006; 4:e39.

61. Esquela AF, Lee SJ. Regulation of metanephric kidney development by growth/differentiation factor 11. Dev Biol. $2003 ; 257: 356-370$.

62. Yu J, McMahon AP, Valerius MT. Recent genetic studies of mouse kidney development. Curr Opin Genet Dev. 2004; 14:550-557.

63. Koury MJ, Ponka P. New insights into erythropoiesis: the roles of folate, vitamin B12, and iron. Annu Rev Nutr. 2004; 24:105-131.

64. Pak M, Lopez MA, Gabayan V, Ganz T, Rivera S. Suppression of hepcidin during anemia requires erythropoietic activity. Blood. 2006; 108:3730-3735.

65. Tonelli M, Hemmelgarn B, Reiman T, Manns B, Reaume MN, Lloyd A, Wiebe N, Klarenbach S. Benefits and harms of erythropoiesis-stimulating agents for anemia related to cancer: a meta-analysis. CMAJ. 2009; 180:E62-71.

66. Yamagishi S, Matsui T, Kurokawa Y, Fukami K. Serum Levels of Growth Differentiation Factor 11 Are Independently Associated with Low Hemoglobin Values in Hemodialysis Patients. Biores Open Access. 2016; 5:155-158.

67. Han Y, Wang H, Fu R, Qu W, Ruan E, Wang X, Wang G, Wu Y, Liu H, Song J, Guan J, Xing L, Li L, et al. GDF11 level in patients with myelodysplastic syndrome and its clinical significance. Zhonghua Yi Xue Za Zhi. 2016; 96:620-624.

68. Kim A, Nemeth E. New insights into iron regulation and erythropoiesis. Curr Opin Hematol. 2015; 22:199-205.

69. Paulson RF. Targeting a new regulator of erythropoiesis to alleviate anemia. Nat Med. 2014; 20:334-335.

70. Dussiot M, Maciel TT, Fricot A, Chartier C, Negre O, Veiga J, Grapton D, Paubelle E, Payen E, Beuzard Y, Leboulch P, Ribeil JA, Arlet JB, et al. An activin receptor IIA ligand trap corrects ineffective erythropoiesis in betathalassemia. Nat Med. 2014; 20:398-407.

71. Suragani RN, Cadena SM, Cawley SM, Sako D, Mitchell D, Li R, Davies MV, Alexander MJ, Devine M, Loveday KS, Underwood KW, Grinberg AV, Quisel JD, et al. Transforming growth factor-beta superfamily ligand trap ACE-536 corrects anemia by promoting late-stage erythropoiesis. Nat Med.2014; 20:408-414.

72. Han Y, Zhang GC, Wang HQ, Fu R, Xing LM, Li LJ, Jiang HJ, Zhang W, Tao JL, Shao ZH. GDF11 is increased in patients with myelodysplastic syndrome. Int J Clin Exp Pathol. 2016; 9:6031-6038.

73. Cao XL, Zhao MF, Li DG, Xing Y, Chen J, HE XY. Chronic Iron Overload Damage the Erythropoiesis in MDS Mouse 
By Increasing GDF11 and ROS Levels. Blood. 2015; 126:2144.

74. Blagosklonny MV. Rapamycin extends life- and health span because it slows aging. Aging (Albany NY). 2013; 5:592-598. https://doi.org/10.18632/aging.100591.

75. Harrison DE, Strong R, Sharp ZD, Nelson JF, Astle CM, Flurkey K, Nadon NL, Wilkinson JE, Frenkel K, Carter CS, Pahor M, Javors MA, Fernandez E, et al. Rapamycin fed late in life extends lifespan in genetically heterogeneous mice. Nature. 2009; 460:392-395.

76. de Cabo R, Carmona-Gutierrez D, Bernier M, Hall MN, Madeo F. The search for anti-aging interventions: From elixirs to fasting regimens. Cell. 2014; 157:1515-1526.

77. Poggioli T, Vujic A, Yang P, Macias-Trevino C, Uygur A, Loffredo FS, Pancoast JR, Cho M, Goldstein J, Tandias RM, Gonzalez E, Walker RG, Thompson TB, et al. Circulating Growth Differentiation Factor 11/8 Levels Decline With Age. Circ Res. 2016; 118:29-37.

78. Brack AS. Ageing of the heart reversed by youthful systemic factors! EMBO J. 2013; 32:2189-2190.

79. Andersen RE, Lim DA. An ingredient for the elixir of youth. Cell Res. 2014; 24:1381-1382.

80. Hall SS. Young blood.Science. 2014; 345:1234-1237.

81. Kaiser J. Aging. 'Rejuvenation factor' in blood turns back the clock in old mice. Science. 2014; 344:570-571.

82. Zhou Y, Jiang Z, Harris EC, Reeves J, Chen X, Pazdro R. Circulating Concentrations of Growth Differentiation Factor 11 Are Heritable and Correlate With Life Span. J Gerontol A Biol Sci Med Sci. 2016; 71:1560-1563.

83. Zhang Y, Li Q, Liu D, Huang Q, Cai G, Cui S, Sun X, Chen X. GDF11 improves tubular regeneration after acute kidney injury in elderly mice. Sci Rep. 2016; 6:34624.

84. Schafer MJ, Atkinson EJ, Vanderboom PM, Kotajarvi B, White TA, Moore MM, Bruce CJ, Greason KL, Suri RM, Khosla S, Miller JD, Bergen HR, LeBrasseur NK. Quantification of GDF11 and Myostatin in Human Aging and Cardiovascular Disease. Cell Metab. 2016; 23:1207-1215.

85. Rodgers BD, Eldridge JA. Reduced Circulating GDF11 Is Unlikely Responsible for Age-dependent Changes in Mouse Heart, Muscle, and Brain. Endocrinology. 2015; 156:3885-3888.

86. Rinaldi F, Zhang Y, Mondragon-Gonzalez R, Harvey J, Perlingeiro RC. Treatment with rGDF11 does not improve the dystrophic muscle pathology of mdx mice. Skelet Muscle. 2016; 6:21.

87. Hinken AC, Powers JM, Luo G, Holt JA, Billin AN, Russell AJ. Lack of evidence for GDF11 as a rejuvenator of aged skeletal muscle satellite cells. Aging Cell. 2016; 15:582-584.

88. Glass DJ. Elevated GDF11 Is a Risk Factor for Age-Related Frailty and Disease in Humans. Cell Metab. 2016; 24:7-8.

89. Freitas-Rodríguez S, Rodríguez F, Folgueras AR. GDF11 administration does not extend lifespan in a mouse model of premature aging. Oncotarget. 2016; 7:55951-55956. https:// doi.org/ 10.18632/oncotarget.11096.
90. Adela R, Reddy P N, Banerjee SK. Alteration of plasma GDF-11 levels in type 2 diabetes patients with cardiovascular complications: A pilot study. J Pract Cardiovasc Sci. 2015; 1:262.

91. Fadini GP, Menegazzo L, Bonora BM, Mazzucato M, Persano S, Vigili de Kreutzenberg S, Avogaro A. Effects of Age, Diabetes, and Vascular Disease on Growth Differentiation Factor 11: First-in-Human Study. Diabetes Care. 2015; 38:e118-119.

92. Li H, Li Y, Xiang L, Zhang J, Zhu B, Xiang L, Dong J, Liu M, Xiang G. GDF11 Attenuates Development of Type 2 Diabetes via Improvement of Islet $\beta$ cell Function and Survival. Diabetes. 2017. pii: db170086.

93. Jing YY, Li D, Wu F, Gong LL, Li R. GDF11 does not improve the palmitate induced insulin resistance in $\mathrm{C} 2 \mathrm{C} 12$. Eur Rev Med Pharmacol Sci. 2017; 21:1795-1802.

94. Olson KA, Beatty AL, Heidecker B, Regan MC, Brody EN, Foreman T, Kato S, Mehler RE, Singer BS, Hveem K, Dalen H, Sterling DG, Lawn RM, et al. Association of growth differentiation factor $11 / 8$, putative anti-ageing factor, with cardiovascular outcomes and overall mortality in humans: analysis of the Heart and Soul and HUNT3 cohorts. Eur Heart J. 2015; 36:3426-3434.

95. Du GQ, Shao ZB, Wu J, Yin WJ, Li SH, Wu J, Weisel RD, Tian JW, Li RK. Targeted myocardial delivery of GDF11 gene rejuvenates the aged mouse heart and enhances myocardial regeneration after ischemia-reperfusion injury. Basic Res Cardiol. 2017; 112:7.

96. Finkenzeller G, Stark GB, Strassburg S. Growth differentiation factor 11 supports migration and sprouting of endothelial progenitor cells. J Surg Res. 2015; 198:50-56.

97. Akhurst RJ, Derynck R. TGF-beta signaling in cancer--a double-edged sword. Trends Cell Biol. 2001; 11:S44-51.

98. Massagué J. TGFbeta in Cancer. Cell. 2008; 134:215-230.

99. Lebrun JJ. The Dual Role of TGF $\beta$ in Human Cancer: From Tumor Suppression to Cancer Metastasis. ISRN Mol Biol. 2012; 2012:381428.

100. Yokoe T, Ohmachi T, Inoue H, Mimori K, Tanaka F, Kusunoki M, Mori M. Clinical significance of growth differentiation factor 11 in colorectal cancer. Int $\mathrm{J}$ Oncol. 2007; 31:1097-1101.

101. Alvarez C, Aravena A, Tapia T, Rozenblum E, Solís L, Corvalán A, Camus M, Alvarez M, Munroe D, Maass A, Carvallo P. Different Array CGH profiles within hereditary breast cancer tumors associated to BRCA1 expression and overall survival. BMC Cancer. 2016; 16:219.

102. Auguściak-Duma A, Sieroń AL. Molecular characteristics of leiomyoma uteri based on selected compounds of the extracellular matrix. Postepy Hig Med Dosw (Online). 2008; 62:148-165.

103. Nakashima M, Mizunuma K, Murakami T, Akamine A. Induction of dental pulp stem cell differentiation into odontoblasts by electroporation-mediated gene delivery of growth/differentiation factor 11 (Gdf11). Gene Ther. 2002; 9:814-818. 
104. Nakashima M, Tachibana K, Iohara K, Ito M, Ishikawa M, Akamine A. Induction of reparative dentin formation by ultrasound-mediated gene delivery of growth/differentiation factor 11. Hum Gene Ther. 2003; 14:591-597.

105. Ding Y, Li XR, Yang KY, Huang LH, Hu G, Gao K. Proteomics analysis of gastric epithelial AGS cells infected with Epstein-Barr virus. Asian Pac J Cancer Prev. 2013; 14:367-372.

106. Ma H, Hong M, Duan J, Liu P, Fan X, Shang E, Su S, Guo J, Qian D, Tang Y. Altered cytokine gene expression in peripheral blood monocytes across the menstrual cycle in primary dysmenorrhea: a case-control study. PLoS One. 2013; 8:e55200.

107. Stoikos CJ, Harrison CA, Salamonsen LA, Dimitriadis E. A distinct cohort of the TGFbeta superfamily members expressed in human endometrium regulate decidualization. Hum Reprod. 2008; 23:1447-1456. 